\title{
Intellectual, mnemonic, and frontal functions in dementia with Lewy bodies: A comparison with early and advanced Parkinson's disease
}

\author{
John Joseph Downes ${ }^{\mathrm{a}, \mathrm{b}, *}$, \\ Nicholas M. Priestley ${ }^{\mathrm{b}}$, Mark Doran ${ }^{\mathrm{b}}$, \\ Jose Ferran $^{\mathrm{b}}$, Eric Ghadiali ${ }^{\mathrm{b}}$ and Paul Cooper ${ }^{\mathrm{b}}$ \\ ${ }^{a}$ Department of Psychology, University of Liverpool, \\ $U K$ \\ ${ }^{\mathrm{b}}$ The Walton Centre for Neurology and Neurosurgery, \\ Liverpool, UK
}

Both Parkinson's disease (PD) and dementia with Lewy bodies (DLB) share a common neuropathological marker, the presence of Lewy bodies in brain stem and basal forebrain nuclei. DLB, in addition, is associated with Lewy bodies in the neocortex, and, in it's more common form, with Alzheimer-type pathological markers, particularly amyloid plaques. Published neuropsychological studies have focused on the differential profiles of DLB and Alzheimer's disease (AD). However, it is presently unclear whether DLB should be classified as a variant of $\mathrm{AD}$ or PD. In the present study we compare a healthy age-matched control group with three groups of patients, one with DLB, and two with PD. One of the PD groups was early in the course (PD-E) and the second, more advanced group (PD-A), was matched on severity of cognitive impairment with the DLB group. The results show that DLB was associated with a different pattern of neuropsychological impairment than the PD-A group particularly in tests believed to be mediated by prefrontal cortical regions.

\section{Introduction}

Lewy bodies, the name given to eosinophilic intracytoplasmic inclusions, were first described by Friedrich Lewy in an early neuropathological study of Parkinson's disease (PD) [29]. Numerous subsequent studies support the general conclusion of this early clinico-pathological study, that Lewy bodies in the brainstem are correlated with the classic movement

\footnotetext{
*Corresponding author: John Joseph Downes Ph.D., Department of Psychology, University of Liverpool, Eleanor Rathbone Building, Bedford Street South, Liverpool L69 7ZA, UK; E-mail: down@liverpool.ac.uk.
}

symptoms of PD. However, there now exists substantial evidence that the presence of Lewy bodies in other, subcortical and cortical brain sites, is correlated with cognitive and neuropsychiatric symptoms. The first case descriptions of dementia associated with Lewy bodies appeared almost 50 years after Lewy's observation. Okazaki et al. [34] described two patients with a progressive dementia syndrome in conjunction with a quadriparesis, in whom the major cellular abnormality was Lewy bodies which were distributed widely throughout the brain, including some cortical regions.

Whilst there is now consensus about the pathogenic role of Lewy bodies in dementia, the same cannot be said about the nosology of the condition. Commonly used terms include Parkinson's disease in Alzheimer's disease (AD) [10], Lewy body variant of AD [21], diffuse Lewy body disease [26], and senile dementia of the Lewy body type [36]. The link with AD arises because more detailed neuropathological study of cases presenting with dementia and Lewy bodies have revealed that cortical senile plaques, a marker also of $\mathrm{AD}$, are present in substantial numbers. However, these tend not to share the characteristic features of plaques seen in $\mathrm{AD}$ [27]. Also, neurofibrillary tangles are absent in the majority of cases of dementia with Lewy bodies [22, 28] (but see [18]), and the regional distribution of abnormal neurites in the hippocampus is different in the two conditions [9]. At the very least, there may be two distinct disorders, dementia with Lewy bodies and cortical plaques, the more common variant, and dementia with Lewy bodies but without concomitant Alzheimer-type pathology, the 'rare' form, which may be associated with younger onset [26]. As a result of this confusion, a recent international consortium [31] suggested the use of a more generic term, dementia with Lewy bodies (DLB), simply to reflect the important role of Lewy bodies in symptom formation. In the present study, postmortem analyses were not yet available and we therefore adopt McKeith et al's suggested nomenclature. 
Information about the prevalence of DLB is based largely on postmortem studies examining consecutive series of dementia patients. There is reasonable agreement across these that approximately $20-25 \%$ of cases have pathological features consistent with DLB [3, 15, 37]. Clinical diagnoses given antemortem, however, reveal a bias towards diagnosing DLB as either AD or multi-infarct dementia [3,15], but this is unsurprising given that specific diagnostic criteria for DLB (see below), have only become available in recent years.

The main features of DLB involve a constellation of cognitive, neurological, and psychiatric symptoms. The early cognitive symptoms are in many ways similar to $\mathrm{AD}$, and may include memory loss, difficulties following conversation, and more general problems with everyday activities such as personal finances. Not surprisingly, the most common neurological features are the cardinal parkinsonian ones of tremor, akinesia, rigidity, gait disturbance and abnormal posture. The number and severity of these different types of symptom varies considerably across patients, as does the order in which they emerge [27]. None of the above symptoms would be particularly helpful in the differential diagnosis of DLB, AD, and PD, but other features may hold the promise of greater specificity. Two of these, marked fluctuations in cognitive state and the presence of hallucinations (invariably visual) have been included in the set of diagnostic criteria described by McKeith and colleagues [30,31], and adopted in the present study.

For obvious reasons, neuropsychological studies of cognitive function in DLB have, in all but one case, compared performance with patients with AD. These have revealed some relatively consistent patterns. First, memory performance in DLB is commonly better than that observed in groups of $\mathrm{AD}$ patients [30, 43, 44, 45] (but see [16, 17]). McKeith et al. [30], for example, found that DLB patients performed better on the recall subtest of the Blessed Mental Test. Second, DLB is associated with a severe deficit in visuoperceptual/visuoconstructive abilities $[16,19,21,43,44,45]$. This has been shown even on untimed tasks such as the clock-face test. Thus, both Galasko et al. [16], Salmon et al. [43] and Shimomura et al. [44] found that whilst both DLB and AD patients are equally impaired when required to draw a clock-face to command, the $\mathrm{AD}$ patients improve to a level significantly higher than DLB patients when required to copy the clock-face from a standard. A third finding is that DLB patients are more impaired on tasks believed to be sensitive to frontal lobe function, including verbal fluency [16, 21], and tasks involving an attentional switching component [16, 41, 43].

As pointed out by Galasko et al. [16], knowledge of the neuropathological and neurochemical substrates of specific cognitive deficits will be widened by these types of clinico-pathological study. Whilst the comparison of DLB with AD is important in this respect, the relationship between DLB and PD has been relatively neglected. One reason for this may be that a prevailing model of the neuropathologies of these disorders assumes they lie on a continuum. In other words, what distinguishes PD from DLB is the relative distribution of brainstem and neocortical Lewy bodies, but cases of PD in which a dementia syndrome subsequently develops will be more like DLB in terms of neocortical pathology. Support for this has been provided by the large autopsy series described by Hughes et al. [25], but there are other reports claiming that PD dementia is associated only with pathology involving the classic brainstem and striatal regions, without any cortical involvement [5].

A range of different types of study - clinical, neuropathological, etc. - will be necessary to determine whether DLB is a variant in the AD spectrum, the PD spectrum, or deserves some independent nosological status [4]. We contribute to this endeavour in the present study by comparing groups of patients with DLB and PD on a range of neuropsychological tests selected to evaluate general intellectual functions, memory, in addition to tests believed to be sensitive to prefrontal cortex pathology. There is, in fact, one recent study which has already addressed this issue: Gnanalingham et al. [19] assessed groups of patients with either DLB, PD, or AD, together with a healthy control group on a small battery of neuropsychological tasks and clinical measures designed to evaluate the range and severity of extrapyramidal signs. Performance on tests of attention and frontal lobe function did not discriminate between DLB and AD groups, but both were impaired relative to PD. However, because the DLB patients were reported to have greater severity of dementia than the PD group, little can be said about the disease-specificity of any observed differences. In the present study, therefore, two PD groups were recruited, one early-in-the-course, and a more advanced group in which there was clear evidence of cognitive impairment and which was matched in terms of global intellectual deterioration to the DLB group. 


\section{Methods}

\subsection{Subjects}

A total of 40 subjects were recruited. In the initial phase, patients with DLB were identified. Subsequently, groups of patients with early and advanced PD (PD-E and PD-A respectively), and a group of control subjects were selected so that each was matched to the DLB group in terms of age, education, socioeconomic status, and error score on the National Adult Reading Test - Revised (NART-R) [33]. The NART-R derived IQ estimates confirm that adequate matching was achieved in terms of educational/intellectual criteria. Table 1 gives the relevant descriptive statistics for age and estimated premorbid IQs, together with gender distributions. One-way ANOVAs confirmed non-significant effects for age, $F(3,36)=1.690$, $p=0.186$, and premorbid verbal and performance IQs, both $F<1$.

\subsection{Neurological assessment}

Patients with PD and DLB were drawn from a Movement Disorders Clinic and a Cognitive Function Clinic at the Walton Centre for Neurology and Neurosurgery. All were diagnosed by a consultant neurologist. Standard clinical criteria were used in the diagnosis of idiopathic PD, and McKeith et al's [30] criteria were used in the diagnosis of DLB. Exclusion criteria for both included head injury, stroke or evidence of cerebral iscaemic episodes, evidence of other major neurological illness, or concurrent psychiatric illness. Severity of clinical symptoms in patients with idiopathic PD was assessed using the Hoehn and Yahr rating scale [24]. For the DLB and PD-A groups, severity of cognitive impairment was assessed using the Mini-Mental State exam (MMSE) [14], for which a lower cut-off of 16 was used.

\subsection{Neuropsychological assessment}

\subsubsection{Recruitment phase}

A primary objective of the present study was to compare groups of DLB and PD patients matched in terms of dementia severity. Given the difference in presentation rates between the two conditions, this was achieved in the following way. As patients with DLB were recruited, their NART-R error scores and MMSE scores were used to identify suitable matched PD-A patients. Matching controls subjects and PD-E pa- tients were identified in a similar fashion, but in this case the matching procedure involved just the NART-R error scores. However, for both these subject groups, a MMSE score of less than 28 was used as an exclusion criterion. Data collection was limited by the speed with which DLB patients could be recruited and the complete study was therefore staggered over several months.

\subsubsection{Experimental phase}

Following recruitment to the study, subjects were given the following neuropsychological battery of tests: The Wechsler Adult Intelligence Scale - Revised (WAIS-R) [47]; the Logical Memory (LM) and Visual Reproduction (VR) subtests of the Wechsler Memory Scale - Revised (WMS-R) [48]; the Warrington Recognition Memory tests (WRMT) [46]; different versions of verbal fluency, taken from Downes et al. [13]; the Stroop test. Other tests (not reported here) were also included.

\subsection{Statistical methods}

For all measures, the same statistical approach was adopted. A major objective of the present study was to determine if there exist differences between PD and DLB in the profile of neuropsychological deficits observed. One statistical approach would be to run a series of one-way analysis of variances (ANOVAs), followed by post hoc testing, should the omnibus F test prove significant. This would allow several relevant questions to be addressed. For example, given any two neurological groups, one could determine whether one or both are significantly different from a matched control group, and, additionally, whether the two groups themselves differ reliably on the measure of interest. There is a problem with this approach, however, because post hoc tests, such as Tukey's HSD, are more likely to lead to Type II errors. The reason for this is that the familywise error rate for the complete set of pairwise comparisons in the data set is controlled at the nominal $\alpha$. It follows that using such an approach, there is a danger of incorrectly accepting the specific null hypothesis relating to PD-A and DLB, that no difference exists between these groups. For this reason, the PD-A/DLB difference was identified as the key experimental question and this was tested as a planned comparison. This was achieved by partitioning the overall ANOVA into three single degree of freedom contrasts, allowing three linked experimental questions, framed as pairwise comparisons, to be ad- 
Table 1

Descriptive statistics for age and estimated premorbid IQs

\begin{tabular}{lcccc}
\hline & & & \multicolumn{2}{c}{ NART-R } \\
\cline { 4 - 5 } Group & Gender (M/F) & Age (years) & VIQ $^{a}$ & PIQ $^{b}$ \\
\hline CON $^{c}$ & $6 / 4$ & $64.70(2.00)$ & $110.30(8.30)$ & $110.80(6.03)$ \\
PD-E $^{d}$ & $3 / 7$ & $60.60(9.17)$ & $112.00(8.93)$ & $112.50(7.86)$ \\
PD-A $^{e}$ & $7 / 3$ & $64.90(6.59)$ & $111.30(9.64)$ & $111.70(7.50)$ \\
DLB & $5 / 5$ & $66.40(3.84)$ & $112.00(7.18)$ & $112.80(7.30)$ \\
\hline
\end{tabular}

${ }^{a}$ Verbal IQ

${ }^{b}$ Performance IQ.

${ }^{c}$ Controls.

${ }^{d}$ Early Parkinson's disease.

${ }^{e}$ Advanced Parkinson's disease.

dressed. In addition to the critical comparison between PD-A and DLB, the two other comparisons involved the PD-E and control groups, and the PD-E and PDA groups. Thus, in reverse order, these comparisons allowed us to address whether there was an effect of early PD, whether there was an effect of PD severity, and whether there were distinctive patterns associated with PD-A and DLB. Throughout, we refer to these planned comparisons as $\mathrm{C} 1, \mathrm{C} 2$, and $\mathrm{C} 3$ respectively, and in each case the $t$ statistic is used. Two further points are worthy of note. First, although the planned comparisons are derived from the overall ANOVAs, the results of these can be referred to without the necessary prerequisite that the omnibus $\mathrm{F}$ test be significant. Nevertheless, for completeness, the relevant F statistics are reported in the text. Second, because these comparisons are derived in the manner described, the degrees of freedom for each test is 1 and 36 . However, where there is evidence of non-homogenous variances across groups on any of the measures, $t$ tests are computed using separate variance estimates, in which case the degrees of freedom are adjusted accordingly. In the results which follow, the following convention is adopted. To avoid unnecessary duplication, all means, standard deviations, and the relevant planned comparisons are given in tables, but not referred to in the text, unless to illustrate specific points.

\section{Results}

\subsection{Intellectual function - global measures}

Analysis of intelligence quotients gives information about global intellectual functions, but is also commonly used as an aid for deciding the presence and ex- tent of intellectual deterioration associated with neurodegenerative disease. For clinical purposes, it is important to be able to provide, on an individual basis, some definitive answer concerning the presence or absence of significant intellectual impairment. This can be achieved by comparing the current verbal and performance IQs, and/or by comparing each of these with the relevant premorbid estimate. In the present case, however, we were more interested in using inferential statistics to draw conclusions about population (group) differences. Therefore, the various index scores (premorbid and current), in addition to the clinically derived discrepancy scores are separately compared across groups. The two standard methods, described above, for deriving neuropsychological discrepancy scores, were used. Thus, comparisons were made between estimates of current verbal and performance IQ (cVIQ-cPIQ), and between estimates of premorbid and current IQ, for both verbal (pVIQ-cVIQ) and performance (pPIQ-cPIQ) indexes.

Table 2 shows the means and standard deviations for these various measures, together with the results of the planned comparisons. Differences emerged when measures of current IQ were analysed: cVIQ, $F(3,36)=3.24, p=0.03$; cPIQ, $F(3,36)=23.55$, $p<0.01$. For both of these measures, planned comparisons revealed that there was no evidence that early Parkinson's disease was associated with specific deficits relative to controls, but there was an effect of PD severity which was evident only as a trend for cVIQ, but was reliable in the case of cPIQ. The DLB group, however, was not reliably different from the PDA group on either of these measures. For the NART-R derived estimates of premorbid IQ, results showed that all groups were matched on both measures: pVIQ and pPIQ, both $F<1$.

The results for the premorbid-current discrepancy scores essentially mirrored these findings: VIQdisc, 
Table 2

Means, standard deviations, and planned comparisons for premorbid and current IQ estimates, and derived discrepancy scores

\begin{tabular}{|c|c|c|c|c|c|c|c|}
\hline \multirow{3}{*}{ Measure } & \multirow{2}{*}{\multicolumn{4}{|c|}{ Group }} & \multicolumn{3}{|c|}{$\begin{array}{c}\text { Planned comparisons } \\
{[t \text { value, probability value, (df error) }]}\end{array}$} \\
\hline & & & & & \multirow{2}{*}{$\frac{\mathrm{C} 1}{\mathrm{CON} / \mathrm{PD}-\mathrm{E}}$} & \multirow{2}{*}{$\frac{\mathrm{C} 2}{\mathrm{PD}-\mathrm{E} / \mathrm{PD}-\mathrm{A}}$} & \multirow{2}{*}{$\frac{\mathrm{C} 3}{\mathrm{PD}-\mathrm{A} / \mathrm{DLB}}$} \\
\hline & $\mathrm{CON}$ & PD-E & PD-A & DLB & & & \\
\hline cVIQ & $105.70(6.95)$ & $108.90(7.29)$ & $97.20(17.48)$ & $94.10(13.87)$ & $\begin{array}{c}1.01,>0.10 \\
(18)\end{array}$ & $\begin{array}{l}1.95,0.07 \\
\quad(12)\end{array}$ & $\begin{array}{c}0.43,>0.10 \\
(17)\end{array}$ \\
\hline cPIQ & $108.80(9.33)$ & $105.00(9.25)$ & $85.20(8.39)$ & $83.50(7.06)$ & $\begin{array}{c}0.99,>0.10 \\
(36)\end{array}$ & $\begin{array}{c}5.17,<0.01 \\
(36)\end{array}$ & $\begin{array}{c}0.44,>0.10 \\
(36)\end{array}$ \\
\hline pVIQ & $110.30(8.30)$ & $112.00(8.93)$ & $111.30(9.64)$ & $112.00(7.18)$ & $\begin{array}{c}0.44,>0.10 \\
(36)\end{array}$ & $\begin{array}{c}0.18,>0.10 \\
\quad(36)\end{array}$ & $\begin{array}{c}0.18,>0.10 \\
(36)\end{array}$ \\
\hline pPIQ & $110.80(6.03)$ & $112.50(7.86)$ & $111.70(7.50)$ & $112.80(7.30)$ & $\begin{array}{c}0.53,>0.10 \\
(36)\end{array}$ & $\begin{array}{c}0.25,>0.10 \\
(36)\end{array}$ & $\begin{array}{c}0.34,>0.10 \\
(36)\end{array}$ \\
\hline \multicolumn{8}{|l|}{$\begin{array}{l}\text { Discrepancy } \\
\text { scores }\end{array}$} \\
\hline pVIQ-cVIQ & $4.60(3.24)$ & $3.10(8.20)$ & $14.10(9.50)$ & $17.90(9.72)$ & $\begin{array}{c}0.41,>0.10 \\
(36)\end{array}$ & $\begin{array}{c}3.04,<0.01 \\
(36)\end{array}$ & $\begin{array}{c}1.05,>0.10 \\
(36)\end{array}$ \\
\hline pPIQ-cPIQ & $2.00(5.23)$ & $7.50(7.71)$ & $26.50(7.60)$ & $29.30(9.10)$ & $\begin{array}{c}1.63,>0.10 \\
(36)\end{array}$ & $\begin{array}{c}5.63,<0.01 \\
(36)\end{array}$ & $\begin{array}{c}0.83,>0.10 \\
(36)\end{array}$ \\
\hline cVIQ-cPIQ & $-3.10(5.28)$ & $3.90(4.82)$ & 12.00 (11.94) & $10.60(12.10)$ & $\begin{array}{l}3.10,<0.01 \\
(18)\end{array}$ & $\begin{array}{l}\text { 1.99, } 0.07 \\
\quad(12)\end{array}$ & $\begin{array}{c}0.26,>0.10 \\
(18)\end{array}$ \\
\hline
\end{tabular}

$F(3,36)=7.92, p<0.01 ;$ PIQdisc, $F(3,36)=$ $32.53, p<0.01$. Thus, for both verbal and performance IQ, the PD-E group was matched to controls, there was a large effect of PD severity, but the difference between PD-A and DLB was unreliable. When the discrepancy between current verbal and performance IQ was examined, however, there was evidence that the PD-E score was significantly greater than the controls'. This may relate to the fact that performance IQ was higher than verbal IQ in the control group, thereby produced a negative value for the discrepancy score. To evaluate this further, the discrepancy scores were subjected to one sample t-tests to evaluate the stricter hypothesis, that the difference between verbal and performance IQs was significantly greater than zero. This was found to be true for the three patient groups, PD-E $t(9)=2.56$, PD-A $t(9)=3.18$, DLB $t(9)=2.77$ (all $p<0.05$ ), but not for the controls, $t(9)=1.86, p=0.10$.

\subsection{Intellectual function - subtest scores}

Of the nine WAIS-R subtests which were completed, there was evidence from the overall ANOVAs that differences were present for four of these: Arithmetic, $F(3,36)=9.62, p<0.01$; Picture Completion, $F(3,36)=9.74, p<0.01$; Picture Arrangement, $F(3,36)=5.24, p<0.01$; and Block Design,
$F(3,36)=5.51, p<0.01$. For the remaining five tests, all $\mathrm{F}$ tests were unreliable, nor was there evidence from the planned comparisons of any non-significant trends: Information, $F(3,36)=1.70, p>0.10$; Digit Span, $F(3,36)=1.64, p>0.10$; Vocabulary, $F(3,36)<1$; Comprehension, $F(3,36)=1.58$, $p>0.10$; Similarities, $F(3,36)<1$. Again, the pattern observed is consistent with that observed for the index scores - five out of six of the Verbal subtests showed no differences, and all three of the Performance subtests revealed reliable differences. Relevant descriptive statistics, together with the results of the planned comparisons, are shown in Table 3.

For three of the four subtests on which group differences emerged, a similar pattern of effects across the planned comparisons was evident. Thus, for Picture Completion, Picture Arrangement, and Block Design, there was a general effect of pathology, with the PD-E group scoring lower than the controls, and, in two out of three cases (Picture Completion and Block Design) a significant effect of PD severity. However, there was no evidence that the DLB group was any worse than the PD-A group. In contrast, for the Arithmetic subtest, there was an effect of PD (relative to controls), no effect of PD severity, but the DLB group was found to perform at a level significantly worse than the PD-A group. 
Table 3

Means, standard deviations and planned comparisons for WAIS-R subtests

\begin{tabular}{|c|c|c|c|c|c|c|c|}
\hline \multirow{3}{*}{$\begin{array}{l}\text { WAIS-R } \\
\text { subtest }\end{array}$} & \multirow{2}{*}{\multicolumn{4}{|c|}{ Group }} & \multicolumn{3}{|c|}{$\begin{array}{c}\text { Planned comparisons } \\
{[t \text { value, probability value, (df error) }]}\end{array}$} \\
\hline & & & & & \multirow{2}{*}{$\frac{\mathrm{C} 1}{\mathrm{CON} / \mathrm{PD}-\mathrm{E}}$} & \multirow{2}{*}{$\frac{\mathrm{C} 2}{\mathrm{PD}-\mathrm{E} / \mathrm{PD}-\mathrm{A}}$} & \multirow{2}{*}{$\frac{\mathrm{C} 3}{\mathrm{PD}-\mathrm{A} / \mathrm{DLB}}$} \\
\hline & $\mathrm{CON}$ & PD-E & PD-A & DLB & & & \\
\hline Information & $10.80(1.87)$ & $9.80(1.14)$ & $10.80(1.75)$ & $9.30(2.31)$ & $\begin{array}{c}1.23,>0.10 \\
(36)\end{array}$ & $\begin{array}{c}1.23,>0.10 \\
(36)\end{array}$ & $\begin{array}{l}\text { 1.85, 0.07 } \\
(36)\end{array}$ \\
\hline Digit span & $11.10(1.45)$ & $11.30(3.23)$ & $9.30(3.68)$ & $8.70(3.86)$ & $\begin{array}{c}0.14,>0.10 \\
(36)\end{array}$ & $\begin{array}{c}1.40,>0.10 \\
(36)\end{array}$ & $\begin{array}{c}0.42,>0.10 \\
(36)\end{array}$ \\
\hline Vocabulary & $10.50(1.96)$ & $11.80(3.05)$ & $10.00(3.97)$ & $10.10(2.60)$ & $0.97,>0.10$ & $\begin{array}{c}1.35,>0.10 \\
(36)\end{array}$ & $\begin{array}{c}0.08,>0.10 \\
(36)\end{array}$ \\
\hline Arithmetic & $11.00(2.05)$ & $8.10(1.10)$ & $8.70(2.95)$ & $6.40(0.97)$ & $\begin{array}{c}3.93,<0.01 \\
(14)\end{array}$ & $\begin{array}{c}0.60,>0.10 \\
(12)\end{array}$ & $\begin{array}{l}2.35,0.04 \\
\quad(11)\end{array}$ \\
\hline Comprehension & $10.40(2.27)$ & $10.10(2.51)$ & $9.00(3.97)$ & 7.80 (2.97) & $\begin{array}{c}0.23,>0.10 \\
(36)\end{array}$ & $\begin{array}{l}0.81,>0.10 \\
(36)\end{array}$ & $\begin{array}{c}0.88,>0.38 \\
(36)\end{array}$ \\
\hline Similarities & $11.30(1.83)$ & $11.70(2.41)$ & $10.10(3.28)$ & $10.90(2.85)$ & $\begin{array}{c}0.34,>0.10 \\
(36)\end{array}$ & $\begin{array}{c}1.35,>0.10 \\
(36)\end{array}$ & $\begin{array}{c}0.68,>0.10 \\
(36)\end{array}$ \\
\hline Pic completion & $12.40(2.50)$ & $10.20(2.86)$ & $7.70(2.45)$ & $6.90(2.28)$ & $\begin{array}{l}\text { 1.94, } 0.06 \\
(36)\end{array}$ & $\begin{array}{l}2.21,0.03 \\
(36)\end{array}$ & $\begin{array}{c}0.71,>0.10 \\
(36)\end{array}$ \\
\hline Pic arrangement & $13.30(1.83)$ & $10.30(2.75)$ & $9.10(2.38)$ & $9.60(3.24)$ & $\begin{array}{l}2.58,0.01 \\
(36)\end{array}$ & $\begin{array}{c}1.03,>0.10 \\
(36)\end{array}$ & $\begin{array}{c}0.43,>0.10 \\
(36)\end{array}$ \\
\hline Block design & $12.20(2.04)$ & $10.20(3.19)$ & $7.90(2.18)$ & $9.30(2.11)$ & $\begin{array}{c}\text { 1.84, } 0.07 \\
(36)\end{array}$ & $\begin{array}{l}2.12,0.04 \\
(36)\end{array}$ & $\begin{array}{c}1.29,>0.10 \\
(36)\end{array}$ \\
\hline
\end{tabular}

\subsection{Memory functions}

For the LM and VR subtests of the WMS-R, two measures were used. The first was the score on the immediate memory test, and the second was an index of forgetting calculated using the following formula: (immediate memory score - delayed memory score)/(immediate memory score). For the WRMT, raw score for the words and faces subtests were used. A preliminary examination of the $\mathrm{F}$ statistics revealed significant effects for all but one of the memory test measures: Logical Memory I, $F(3,36)=$ 8.39, $p<0.01$; verbal forgetting, $F(3,36)=5.77$, $p<0.01$; Visual Reproduction I, $F(3,36)=32.43$, $p<0.01$; Visual forgetting, $F(3,36)<1$; Warrington words, $F(3,36)=7.81, p<0.01$; Warrington faces, $F(3,36)=21.79, p<0.01$. The detailed patterns across the planned comparisons differed however. These, together with the means and standard deviations are shown in Table 4.

For the verbal tests, the PD-E group was impaired relative to the controls on immediate recall and the verbal recall forgetting index, but not on verbal recognition. PD severity was related to a further performance decrement on immediate recall and verbal recognition, but not on the forgetting index. There was no evidence that DLB was associated with larger verbal memory deficits than PD-A. A slightly different picture emerged for the visual memory measures. On Visual Reproduction I, there was no difference between the PD-E group and controls, but there was a significant effect of PD severity, and the difference between the PD-A group and the DLB group was marginally significant. As with the verbal memory measures, rate of forgetting of visual material was faster in the PD-E group than the controls, an effect which did not worsen with PD severity, nor with DLB. Finally, unlike verbal recognition, face recognition was compromised early in the course in PD and increased with severity, but again, there was no evidence that the DLB group was more affected than the PD-A group. Overall, whilst there are clear patterns of deficit relating to $\mathrm{PD}$, some of which show an increase with disease severity, none of the differences between the PD-A and DLB groups were reliable.

\subsection{Frontal functions}

Analysis of those tests believed to be mediated by regions of prefrontal cortex, unlike most of the intellectual and memory test measures described above, revealed strikingly consistent patterns for the com- 
Table 4

Means, standard deviations, and planned comparisons for the memory test measures

\begin{tabular}{|c|c|c|c|c|c|c|c|}
\hline \multirow{3}{*}{$\begin{array}{l}\text { Memory test } \\
\text { measure }\end{array}$} & \multirow{2}{*}{\multicolumn{4}{|c|}{ Group }} & \multicolumn{3}{|c|}{$\begin{array}{c}\text { Planned comparisons } \\
{[t \text { value, probability value, (df error) }]}\end{array}$} \\
\hline & & & & & \multirow{2}{*}{$\frac{\mathrm{C} 1}{\mathrm{CON} / \mathrm{PD}-\mathrm{E}}$} & \multirow{2}{*}{$\frac{\mathrm{C} 2}{\mathrm{PD}-\mathrm{E} / \mathrm{PD}-\mathrm{A}}$} & \multirow{2}{*}{$\frac{\mathrm{C} 3}{\mathrm{PD}-\mathrm{A} / \mathrm{DLB}}$} \\
\hline & $\mathrm{CON}$ & PD-E & PD-A & DLB & & & \\
\hline Logical mem I & $23.30(1.16)$ & $20.80(3.12)$ & $13.60(6.65)$ & $15.90(6.21)$ & $\begin{array}{l}2.38,0.04 \\
(11)\end{array}$ & $\begin{array}{l}\text { 3.10, 0.01 } \\
\text { (13) }\end{array}$ & $\begin{array}{c}0.80,>0.10 \\
(18)\end{array}$ \\
\hline $\begin{array}{l}\text { Logical mem } \\
\text { forgetting }\end{array}$ & $0.23(0.10)$ & $0.48(0.24)$ & $0.54(0.31)$ & $0.69(0.30)$ & $\begin{array}{l}2.19,0.04 \\
(36)\end{array}$ & $\begin{array}{c}0.56,>0.10 \\
(36)\end{array}$ & $\begin{array}{c}1.32,>0.10 \\
(36)\end{array}$ \\
\hline $\begin{array}{l}\text { Visual } \\
\text { reproduction I }\end{array}$ & $29.80(3.88)$ & $28.20(7.81)$ & $14.20(6.53)$ & $9.20(3.16)$ & $\begin{array}{c}0.63,>0.10 \\
(36)\end{array}$ & $\begin{array}{c}5.52,<0.01 \\
(36)\end{array}$ & $\begin{array}{l}1.97,0.06 \\
(36)\end{array}$ \\
\hline $\begin{array}{l}\text { Vis. rep. } \\
\text { forgetting }\end{array}$ & $0.32(0.11)$ & $0.52(0.27)$ & $0.60(0.27)$ & $0.40(0.78)$ & $\begin{array}{l}2.17,0.05 \\
\quad(12)\end{array}$ & $\begin{array}{c}0.66,>0.10 \\
(18)\end{array}$ & $\begin{array}{c}0.74,>0.10 \\
(11)\end{array}$ \\
\hline $\begin{array}{l}\text { Warrington } \\
\text { words }\end{array}$ & $46.20(1.14)$ & $44.30(4.72)$ & $36.90(9.21)$ & $36.60(4.27)$ & $\begin{array}{c}1.24,>0.10 \\
(10)\end{array}$ & $\begin{array}{l}2.62,0.04 \\
\quad(13)\end{array}$ & $\begin{array}{c}0.09,>0.10 \\
(13)\end{array}$ \\
\hline $\begin{array}{l}\text { Warrington } \\
\text { faces }\end{array}$ & $45.30(0.67)$ & $39.80(4.57)$ & $33.60(4.90)$ & $33.60(3.60)$ & $\begin{array}{c}3.77,<0.01 \\
(9)\end{array}$ & $\begin{array}{c}2.93,<0.01 \\
(18)\end{array}$ & $\begin{array}{c}<0.01,>0.10 \\
(17)\end{array}$ \\
\hline
\end{tabular}

Table 5

Means, standard deviations, and planned comparisons for frontal test measures

\begin{tabular}{|c|c|c|c|c|c|c|c|}
\hline \multirow{3}{*}{$\begin{array}{l}\text { Fluency test } \\
\text { measure }\end{array}$} & \multirow{2}{*}{\multicolumn{4}{|c|}{ Group }} & \multicolumn{3}{|c|}{$\begin{array}{c}\text { Planned comparisons } \\
{[t \text { value, probability value, }(\mathrm{df} \text { error })]}\end{array}$} \\
\hline & & & & & \multirow{2}{*}{$\frac{\mathrm{C} 1}{\mathrm{CON} / \mathrm{PD}-\mathrm{E}}$} & \multirow{2}{*}{$\frac{\mathrm{C} 2}{\mathrm{PD}-\mathrm{E} / \mathrm{PD}-\mathrm{A}}$} & \multirow{2}{*}{$\frac{\mathrm{C} 3}{\mathrm{PD}-\mathrm{A} / \mathrm{DLB}}$} \\
\hline & $\mathrm{CON}$ & PD-E & PD-A & DLB & & & \\
\hline $\begin{array}{l}\text { Phonemic } \\
\text { fluency }\end{array}$ & $14.03(0.79)$ & $12.57(2.71)$ & $10.43(2.18)$ & $6.40(4.46)$ & $\begin{array}{c}1.64,>0.10 \\
(11)\end{array}$ & $\begin{array}{l}\text { 1.94, 0.07 } \\
(17)\end{array}$ & $\begin{array}{l}2.57,0.02 \\
\quad(13)\end{array}$ \\
\hline $\begin{array}{l}\text { Category } \\
\text { fluency }\end{array}$ & $16.25(1.77)$ & $15.20(3.45)$ & $10.75(5.03)$ & $5.40(2.73)$ & $\begin{array}{c}0.86,>0.10 \\
(13)\end{array}$ & $\begin{array}{l}2.31,0.04 \\
(16)\end{array}$ & $\begin{array}{l}2.96,0.01 \\
\quad(14)\end{array}$ \\
\hline $\begin{array}{l}\text { Alternating } \\
\text { phonemic }\end{array}$ & $14.60(1.90)$ & $13.30(5.95)$ & $11.30(4.88)$ & $6.00(3.23)$ & $\begin{array}{c}0.66,>0.10 \\
(11)\end{array}$ & $\begin{array}{l}0.82,>0.10 \\
(17)\end{array}$ & $\begin{array}{l}2.86,0.01 \\
\quad(16)\end{array}$ \\
\hline $\begin{array}{l}\text { Alternating } \\
\text { category }\end{array}$ & $14.30(0.95)$ & $13.40(4.43)$ & $9.60(4.60)$ & $5.70(4.03)$ & $\begin{array}{c}0.63,>0.10 \\
(10)\end{array}$ & $\begin{array}{l}\text { 1.88, } 0.08 \\
\quad(18)\end{array}$ & $\begin{array}{l}2.02,0.06 \\
\quad(18)\end{array}$ \\
\hline $\begin{array}{l}\text { Alternating } \\
\text { phon / cat }\end{array}$ & $15.30(2.63)$ & $11.40(5.68)$ & $7.30(4.14)$ & $5.40(3.47)$ & $\begin{array}{l}2.11,0.04 \\
(36)\end{array}$ & $\begin{array}{l}2.22,0.03 \\
(36)\end{array}$ & $\begin{array}{c}1.03,>0.10 \\
(36)\end{array}$ \\
\hline $\begin{array}{l}\text { Stroop } \\
\text { score }\end{array}$ & $75.50(9.45)$ & $79.30(24.18)$ & $55.10(27.21)$ & $24.20(18.55)$ & $\begin{array}{c}0.41,>0.10 \\
(36)\end{array}$ & $\begin{array}{l}2.58,0.01 \\
(36)\end{array}$ & $\begin{array}{c}3.30,<0.01 \\
(12)\end{array}$ \\
\hline $\begin{array}{l}\text { Stroop } \\
\text { errors }\end{array}$ & $3.10(1.66)$ & $3.30(4.55)$ & $4.70(3.68)$ & $11.00(8.65)$ & $\begin{array}{c}0.13,>0.10 \\
(11)\end{array}$ & $\begin{array}{c}0.76,>0.10 \\
(17)\end{array}$ & $\begin{array}{l}2.12,0.05 \\
(12)\end{array}$ \\
\hline $\begin{array}{l}\text { Stroop } \\
\% \text { errors }\end{array}$ & $3.97(2.03)$ & $4.17(5.15)$ & 8.77 (8.57) & $36.95(22.51)$ & $\begin{array}{c}0.11,>0.10 \\
(12)\end{array}$ & $\begin{array}{c}1.45,>0.10 \\
(15)\end{array}$ & $\begin{array}{c}3.70,<0.01 \\
(12)\end{array}$ \\
\hline
\end{tabular}

parison between PD-A and DLB. As might be expected, omnibus $\mathrm{F}$ tests were significant for all of the fluency measures: single and alternating phonemic, $F(3,36)=13.51, p<0.01, F(3,36)=7.83$, $p<0.01$ respectively; single and alternating category, $F(3,36)=20.49, p<0.01, F(3,36)=10.70$, $p<0.01$ respectively; and the alternating phonemic/category task, $F(3,36)=11.40, p<0.01$. The three Stroop measures showed a similar pattern: overall score, $F(3,36)=14.48, p<0.01$; total errors, $F(3,36)=4.94, p<0.01$; percent errors, $F(3,36)=16.38, p<0.01$.

The specific pairwise comparisons revealed that on only one fluency measure, the alternating phonemic/category task, did the PD-E group perform significantly worse than the controls. On all other fluency 
tasks, both single and alternating, the differences were unreliable. PD severity, however, did have an effect: The PD-A group was significantly worse than the PD-E group on four of the five measures, the only exception being alternating phonemic. Similarly, the DLB group was significantly worse than the PD-A group on four of five measures, although in this case, the unreliable difference was on the alternating phonemic/category task.

Stroop performance was also severely compromised in DLB, with each of the three comparisons with PDA achieving significance. As with the fluency measures, there was little evidence of a PD-related deficit, although in this case, there were not even numerical trends in the PD-E and control means. PD severity had no effect on the number of errors committed, but there was an effect on overall score. The fact that the percent error score was also not reliably different between PD-E and PD-A groups, suggests that patients in the latter group may have been experiencing difficulties but maintained a fairly constant error rate. In contrast, the DLB group were impaired on all three measures. When the percent error scores are considered, the extent of this impairment becomes most apparent: Almost $40 \%$ of responses given by the DLB group were erroneous, whereas between approximately $5-10 \%$ errors were given by the other three groups.

\section{Discussion}

In this study, performance on a range of intellectual, mnemonic, and frontal test measures was examined in three groups of patients, two with idiopathic PD and one with DLB, together with a matched healthy control group. The two groups of patients with PD were selected to vary in severity and also in terms of cognitive impairment. As such, both these factors were confounded, and the PD-A scores cannot be taken as representative of the population of advanced PD cases. However, the main objective of the present study was to determine whether there exist differences between PD and DLB when dementia, as indexed by various measures of intellectual performance, was matched across the groups. As noted above, there was clear evidence that this matching procedure was successful: The PD-A group was significantly impaired relative to the PD-E group on both indexes of current IQ, and on each of the three discrepancy scores, but there was no evidence that the DLB group was more impaired on any of these measures. Taken together with the finding that all four groups were matched in terms of estimated premorbid IQ, any observed group differences on the other neuropsychological measures can be safely attributed to disease-specific processes, rather than simply being an artefact of dementia severity. In the discussion which follows, attention is focused mainly on the observed patterns for the PD-A/DLB comparisons.

Analysis of the individual WAIS-R subtests revealed PD- and DLB-related patterns. Although the difference between the PD-E group and controls was nonsignificant for the global measure of performance IQ, small but reliable differences did emerge on the three contributing subtests, picture completion, block design, and picture arrangement. For the first two of these, there was a further significant decrement in performance associated with PD severity but the PD-A and DLB groups did not differ on any of these measures. This may seem a surprising outcome, given that DLB patients have consistently performed at a low level on a range of visuoperceptual, visuospatial and visuoconstructive tests when compared with AD patients matched on dementia severity, e.g., [44]. However, it is also known that AD patients are not reliably different from controls, but non-demented PD patients are impaired, on a version of simultaneous matchingto-sample which has a high visuoperceptual load [40]. Thus, visuoperceptual deficits of this type may not be dementia-related, but linked with brain stem pathology and related striatal dopaminergic disruption associated with both PD and DLB.

The DLB group did perform at a significantly lower level than the PD-A group, however, on two of the verbal subtests. The observed significant effect on the Information subtest is somewhat puzzling, but the difference on the Arithmetic subtest may be related to the fact that the more difficult problems rely heavily on working memory. There is convergent evidence from both animal [20] and human lesion studies [38], together with more recent evidence from functional imaging, e.g., [7] that many working memory functions are frontally mediated. Thus, the finding that DLB is associated with a greater impairment than PD on this task, when matched on dementia severity, suggests more extensive frontal pathology in the former. It is noteworthy that the PD-E group was also impaired on this subtest, and a similar finding has been reported by Sagar and colleagues using a digit ordering task [6]. One possibility which is explored in greater detail below, is that performance on certain tasks mediated by prefrontal cortical regions can be disrupted in two ways, the first involving a striato-frontal disconnection 
which is common to both PD and DLB, and the second involving cortically based pathological changes which are more prevalent in DLB.

The results from the memory test measures were unremarkable in the sense that there was limited evidence that the DLB group was more impaired than the PD-A group. The only task on which a significant difference emerged was visual reproduction, but without the appropriate control condition it is unclear whether this pattern reflects a true visual memory impairment or is an artefact of group differences in visuoconstructive ability. As noted above, though, there is little additional evidence in the present data-set to support such differences.

The pattern of results from the set of frontal tests are not inconsistent with the hypothesis outlined above, that impaired performance on such tasks might result from either a subcortical disconnection or cortical pathology. The DLB group was more severely impaired than the PD-A group on 7 out of 8 of these measures. Across the different fluency tasks, the performance of both groups of PD patients was consistent with the results of our earlier study [13]. Thus, the PDE patients were matched to the healthy control subjects on all the different versions of fluency task, apart from the alternating phonemic/category task, and a similar pattern can be inferred for the PD-A group because they were impaired relative to the PD-E group on all of these. The DLB group, in contrast, was impaired on all tasks apart from the alternating phonemic/category task. It is worth pointing out the extent of the DLBrelated impairment. The same low output, averaging approximately 5.8 words/minute, was observed on all five tasks, and in some cases, this was little more than half the observed mean output for the PD-A group. A similar marked deficit in performance was observed for the Stroop.

The proposal that 'frontal' task performance is mediated by interacting cortical and subcortical mechanisms is beginning to receive increasing support, particularly from studies comparing patients with basal ganglia disease, like PD, and patients with selective frontal lesions. Owen et al. [35], for example, have demonstrated that set-shifting deficits reported in both PD patients, e.g., [12] and frontal patients, e.g., [32] may involve fundamentally different, though related, cognitive processes. More recently, Robbins' group have provided evidence that a simple task-switching paradigm involves dissociative executive mechanisms mediated by dopaminergic transmission along the nigrostriatal pathway and regions of left prefrontal cor- tex [39]. In relation to PD and DLB, we propose that the pattern of deficits observed across the different tasks might also reflect the differential pathological involvement of subcortical and frontal cortical regions. Additional support for this comes from a recent MRI study in which regional brain atrophy was examined in groups of PD and DLB patients, both of which were described as demented. Although frontal atrophy was a feature of both these conditions, this differed in degree, with the PD group showing only mild atrophy and the DLB showing significant atrophy [11]. Finally, one of the cortical regions found to have a dense population of Lewy bodies is the cingulate cortex, which has been associated with a number of attentional/executive functions [8]. Harrington et al. [23], in a recent postmortem study, demonstrated that DLB is characterised by relatively high densities of cortical Lewy bodies in this region, compared with the lower numbers found in both non-demented and cognitively impaired PD.

\section{Acknowledgements}

We would like to thank Dr. N. Fletcher for referring many of the patients.

\section{References}

[1] G. Blessed, B.E. Tomlinson and M. Roth, The association between quantitative measures of dementia and of senile change in the cerebral grey matter of elderly subjects, British Journal of Psychiatry 114 (1968), 797-811.

[2] E.J. Byrne, G.G. Lennox, R.B. Godwin-Austin, D. Jefferson, J. Lowe, R.J. Mayer, M. Landon and F.J. Doherty, Dementia associated with Cortical Lewy bodies: Proposed clinical diagnostic criteria, Dementia 2 (1991), 283-284.

[3] E.J. Byrne, G.G. Lennox, J. Lowe and R.B. GodwinAustin, Diffuse Lewy body disease: Clinical features in 15 cases, Journal of Neurology, Neurosurgery and Psychiatry 52 (1989), 709-717.

[4] S.P. Cercy and F.W. Bylsma, Lewy bodies and progressive dementia: A critical review and meta-analysis, Journal of the International Neuropsychological Society 3 (1997), 179-194.

[5] H.C. Chui, J.A. Mortimer, Y.U. Slager, C. Zarow, W. Bondareff and D.D. Webster, Pathologic correlates of dementia in Parkinson's disease, Archives of Neurology 43 (1986), 991-995.

[6] J.A. Cooper, H.J. Sagar, N. Jordan, N.S. Harvey and E.V. Sullivan, Cognitive impairment in early, untreated Parkinson's disease and it's relationship to motor disability, Brain 114 (1991), 2095-2122.

[7] S.M. Courtney, L.G. Ungerleider, K. Keil and J.V. Haxby, Object and spatial visual working memory activate separate neural systems in human cortex, Cerebral Cortex 6 (1996), 39-49. 
[8] O. Devinsky, M.J. Morrell and B.A. Vogt, Contributions of anterior cingulate cortex to behaviour, Brain 118 (1995), 279306.

[9] D.W. Dickson, D. Ruan, H. Crystal, M.H. Mark, P. Davies, Y Kres and S.-H. Yen, Hippocampal degeneration differentiates diffuse Lewy body disease (DLBD) from Alzheimer's disease: Light and electron microscopic immunocytochemistry of CA2-3 neurites specific to DLBD, Neurology 41 (1991), 1402-1409.

[10] S.M. Ditta and S.S. Mirra, Neuropathologic and clinical features of Parkinson's disease in Alzheimer's disease, Neurology 37 (1987), 754-760.

[11] K.L. Double, G.M. Halliday, D.A. McRitchie, W.G. Reid, M.A. Hely and J.G. Morris, Regional brain atrophy in idiopathic Parkinson's disease and diffuse Lewy body disease, Dementia 7 (1996), 304-313.

[12] J.J. Downes, A.C. Roberts, B.J. Sahakian, J.L. Evenden, R.G Morris and T.W. Robbins, Impaired extra-dimensional shift performance in medicated and unmedicated Parkinson's disease; Evidence for a specific attentional dysfunction, $\mathrm{Neu}$ ropsychologia 27 (1989), 1329-1343.

[13] J.J. Downes, H.M. Sharp, B. Costall, H.J. Sagar and J. Howe, Alternating fluency in Parkinson's Disease: An evaluation of the control theory of cognitive impairment, Brain 116 (1993), 887-902.

[14] M.F. Folstein, S.E. Folstein and P.R. McHugh, 'Mini-Mental State': A practical method for grading the cognitive state of patients for the clinician, Journal of Psychiatric Research 48 (1975), 189-198

[15] D. Galasko, L.A. Hansen, R. Katzman, W. Wiederholt, E. Masliah, R. Terry, L.R. Hill, P. Lessin and L.J. Thal, Clinicalneuropathological correlations in Alzheimer's disease and related dementias, Archives of Neurology 51 (1994), 888895.

[16] D. Galasko, R. Katzman, D.P. Salmon and L. Hansen, Clinical and neuropathological findings in Lewy body dementias, Brain and Cognition 31 (1996), 166-175.

[17] P.H. Galloway, A. Sahgal, I.G. McKeith, S. Lloyd, J.H. Cook, I.N. Ferrier and J.A. Edwardson, Visual pattern recognition memory and learning deficits in senile dementias of Alzheimer and Lewy body types, Dementia 3 (1992), 101107.

[18] M. Gearing, M. Lynn and S. Mirra, Neurofibrillary pathology in Alzheimer's disease with Lewy bodies, Archives of Neurology 56 (1999), 203-208.

[19] K.K. Gnanalingham, E.J. Byrne, A. Thornton, M.A. Sambrook and P. Bannister, Motor and cognitive function in Lewy body dementia: Comparison with Alzheimer's disease and Parkinson's disease, Journal of Neurology, Neurosurgery and Psychiatry 62 (1997), 243-252.

[20] P.S. Goldman-Rakic, Circuitry of primate prefrontal cortex and regulation of behaviour by representational memory, in: Handbook of Physiology - The nervous system, vol. V, F. Plum, ed., American Physiology Society, Bethesda, 1987, pp. 373-417.

[21] L.A. Hansen, D. Salmon, D. Galasko, E. Masliah, R. Katzman, R. DeTeresa, L. Thal, M.M. Pay, R. Hofstetter, M.R Klauber, V. Rice, N. Butters and M. Alford, The Lewy Body Variant of Alzheimer's disease: A clinical and pathological entity, Neurology 40 (1990), 1-8.

[22] L.A. Hansen, E. Masliah, S. Quijada-Fawcett and D. Rexin, Entorhinal neurofibrillary tangles in Alzheimer's disease with Lewy bodies, Neuroscience Letters 129 (1991), 269-272.
[23] C.R. Harrington, R.H. Perry, E.K. Perry, J. Hurt, I.G. McKeith, M. Roth and C.M. Wischik, Senile dementia of Lewy body type and Alzheimer type are biochemically distinct in terms of paired helical filaments and hyperphosphorylated tau protein, Dementia 5 (1994), 215-228.

[24] M.M. Hoehn and M.D. Yahr, Parkinsonism: onset, progression and mortality, Neurology 7 (1967), 447-442.

[25] A.J. Hughes, S.E. Daniel, S. Blankson and A.J. Lees, A clinicopathological study of 100 cases of Parkinson's disease, Archives of Neurology 50 (1993), 141-148.

[26] K. Kosaka, Diffuse Lewy body disease in Japan, Journal of Neurology 237 (1990), 197-204.

[27] G. Lennox, Lewy Body Dementia, in: Balliere's Clinical Neurology, vol. 1 no. 3: Unusual dementias, M.N. Rossor, ed., Balliere Tindall, London, 1992, pp. 653-676.

[28] G. Lennox, J. Lowe, M. Landon, E.J. Byrne, R.J. Mayer and R.B. Godwin-Austin, Diffuse Lewy body disease: Correlative neuropathology using anti-ubiquitin using immunocytochemistry, Journal of Neurology, Neurosurgery, and Psychiatry 52 (1989), 1236-1247.

[29] F.H. Lewy, Parlysis agitans. I. Pathologische anatomie, in: Handbook der neurologie, M. Lewandowsky, ed., Springer, Berlin, 1912, pp. 920-933.

[30] I.G. McKeith, R.H. Perry, A.F. Fairbairn, S. Jabeen, and E.K. Perry, Operational criteria for senile dementia of Lewy body type (SDLT), Psychological Medicine 22 (1992), 911-922.

[31] I.G. McKeith, D. Galasko, K. Kosaka, E.K. Perry, D.W. Dickson, L.A. Hansen, D.P. Salmon, J. Lowe, S.S. Mirra, E.J. Byrne, G. Lennox, N.P. Quinn, J.A. Edwardson, P.G. Ince, C. Bergeron, A. Burns, B.L. Miller, S. Lovestone, D. Collerton, E.N. Jansen, C. Ballard, R.A. de Vos, G.K. Wilcock, K.A. Jellinger and R.H. Perry, Consensus guidelines for the clinical and pathologic diagnosis of dementia with Lewy bodies (DLB): Report of the consortium on DLB international workshop, Neurology 47 (1996), 1113-1124.

[32] B. Milner, Some effects of frontal lobectomy in man, in: The Frontal Granular Cortex and Behaviour, J.M. Warren and K. Akert, eds, McGraw-Hill, New York, 1964, pp. 313-334.

[33] H.E. Nelson and J. Willison, National Adult Reading TestRevised, NFER-Nelson, Windsor, 1991.

[34] H. Okazaki, L.E. Lipkin and S.M. Aronson, Diffuse intracytoplasmic ganglionic inclusions (Lewy type) associated with progressive dementia and quadriparesis in flexion, Journal of Neuropathology and Experimental Neurology 20 (1961), 237-244.

[35] A.M. Owen, A.C. Roberts, J.R. Hodges, B.A. Summers, C.E. Polkey and T.W. Robbins, Contrasting mechanisms of impaired attentional set-shifting in patients with frontal lobe damage or Parkinson's disease, Brain 116 (1993), 11591175 .

[36] R.H. Perry, D. Irving, G. Blessed, A. Fairbairn and E.K. Perry, Senile dementia of the Lewy body type. A clinically and neuropathologically distinct form of Lewy body dementia in the elderly, Journal of the Neurological Sciences 95 (1990), 119-139.

[37] R.H. Perry, D. Irving and B.E. Tomlinson, Lewy body prevalence in the aging brain: Relationship to neuropsychiatric disorders, Alzheimer-type pathology and catecholaminergic nuclei, Journal of Neurological Sciences 100 (1990), 223233.

[38] M. Petrides, Deficits on conditional associative learning tasks after frontal- and temporal-lobe lesions in man, Neuropsychologia 23 (1985), 601-614. 
[39] R.D. Rogers, B.J. Sahakian, J.R. Hodges, C.E. Polkey, C. Kennard and T.W. Robbins, Dissociating executive mechanisms of task control following frontal lobe damage and Parkinson's disease, Brain 121 (1998), 815-842.

[40] B.J. Sahakian, R.G. Morris, J.L. Evenden, A. Heald, R. Levy, M. Philpot and T.W. Robbins, A comparative study of visuospatial memory and learning in Alzheimer-type dementia and Parkinson's disease, Brain 111 (1988), 695-718.

[41] A. Sahgal, P.H. Galloway, I.G. McKeith, J.A. Edwardson and S. Loyd, A comparative study of attentional deficits in senile dementias of Alzheimer and Lewy body types, Dementia 3 (1992), 350-354.

[42] A. Sahgal, P.H. Galloway, I.G. McKeith, S. Lloyd, J.H. Cook, N. Ferrier and J.A. Edwardson, Matching to sample deficits in patients with senile dementias of the Alzheimer and Lewy body types, Archives of Neurology 49 (1992), 1043-1046.

[43] D.P. Salmon, D. Galasko, L.A. Hansen, E. Masliah, N. Butters, L.J. Thal and R. Katzman, Neuropsychological deficits associated with diffuse Lewy body disease, Brain and Cognition 31 (1996), 148-165.

[44] T. Shimomura, E. Mori, H. Yamashita, T. Imamura, N. Hirono, M. Hashimoto, S. Tanimukai, H. Kazui and T. Hanihara, Cognitive loss in dementia with Lewy bodies and Alzheimer's disease, Archives of Neurology 55 (1998), 1547-1552.

[45] Z. Walker, R.L. Allen, S. Shergill and C.L. Catona, Neuropsychological performance in Lewy body dementia and Alzheimer's disease, British Journal of Psychiatry 170 (1997), 243-252.

[46] E.K. Warrington, Recognition Memory Test, NFER-Nelson, Windsor, 1984.

[47] D. Wechsler, Wechsler Adult Intelligence Scale - Revised, Psychological Corporation, Harcourt Brace Jovanovich, 1981.

[48] D. Wechsler, Wechsler Memory Scale - Revised, Psychological Corporation, Harcourt Brace Jovanovich, 1987. 


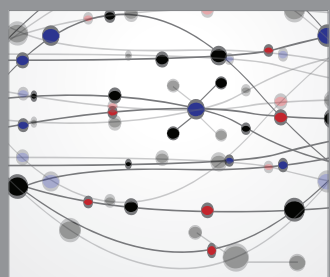

The Scientific World Journal
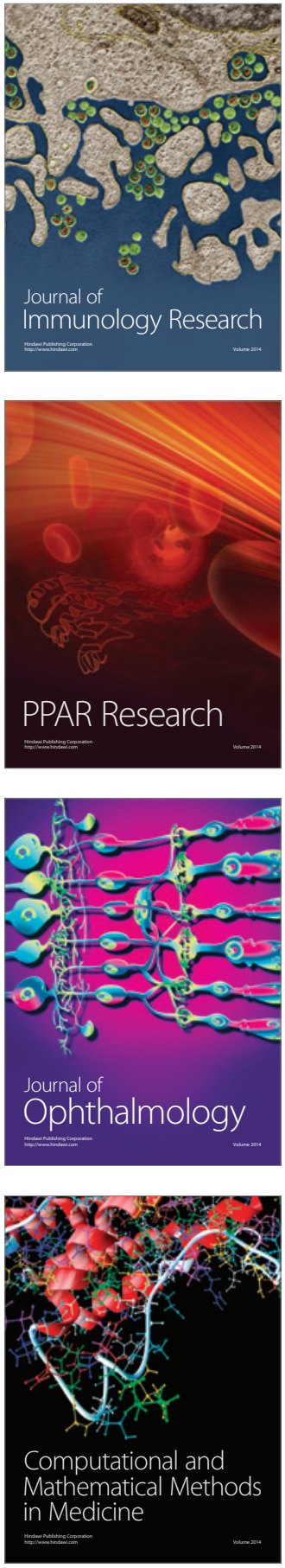

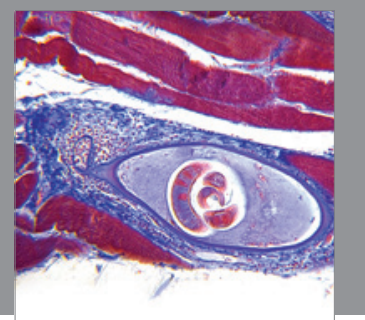

Gastroenterology

Research and Practice
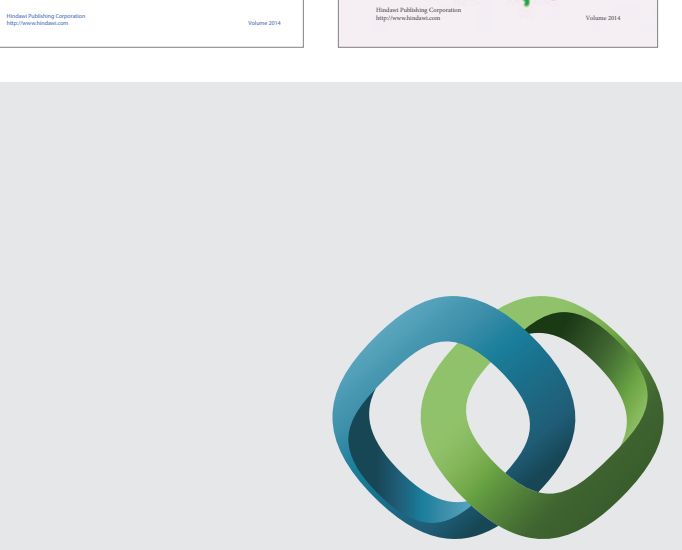

\section{Hindawi}

Submit your manuscripts at

http://www.hindawi.com
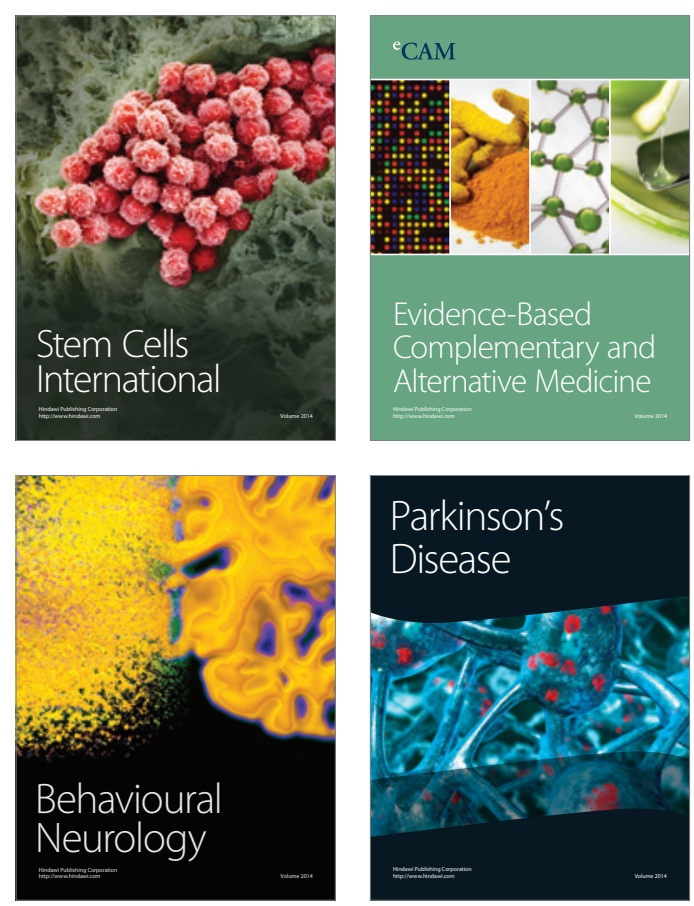

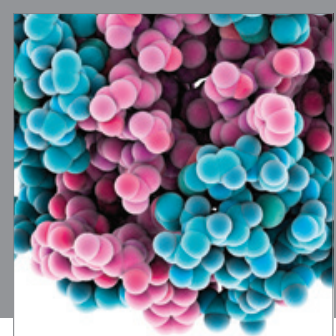

Journal of
Diabetes Research

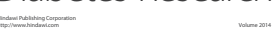

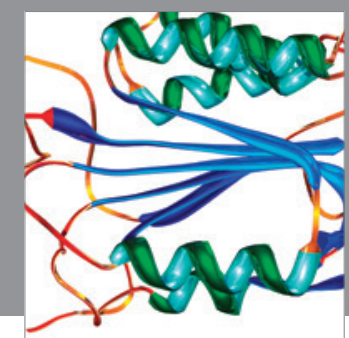

Disease Markers
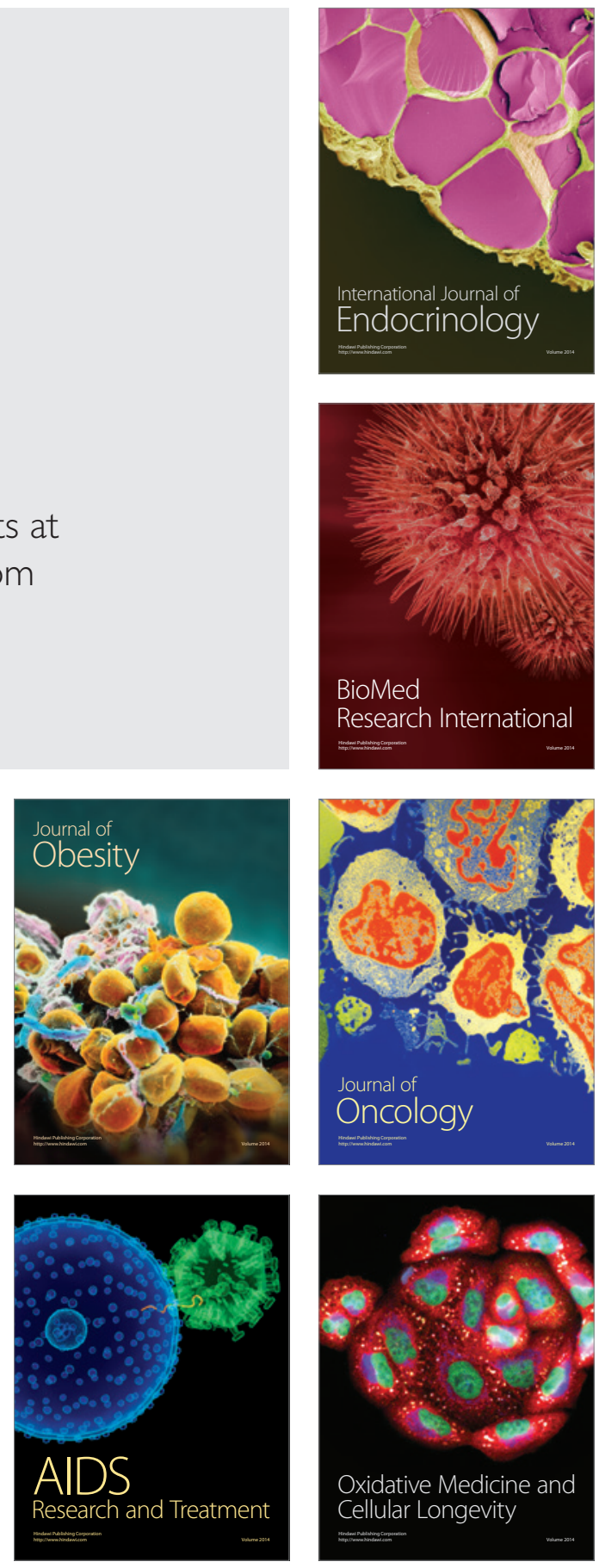